Article

\title{
The Effect of Heat Treatments on the Fatigue Strength of H13 Hot Work Tool Steel
}

\author{
Ruhi Yeşildal ${ }^{*}$ \\ ${ }^{*}$ Correspondence autor \\ Atatürk University Engineering Faculty \\ e-mail:ryesil@atauni.edu.tr \\ Tel:+905065159131-+904422314856
}

\begin{abstract}
The fatigue strength of the hot work steel depends on various factors, including the mechanical, properties and behavior and bulk and the surface under layer, the microstructural features as well as heat treatments. The influence of a series of heat treatments on the fatigue strength of H13 hot work steel was investigated. Different preheating, quenching and tempering treatments were applied to four sets of specimens and fatigue tests were conducted at room temperature using a rotating bending test machine. All heat treatments resulted in a certain improvement of the fatigue strength. Highest fatigue strength obtained by applying a double tempering heat treatment (first tempering at $550{ }^{\circ} \mathrm{C}$ for two hours and second tempering at $610{ }^{\circ} \mathrm{C}$ for two hours) after initial preheating and quenching. One tempering treatment $\left(550{ }^{\circ} \mathrm{C}\right.$ for two hours after preheating and quenching) did not significantly improve the fatigue strength.
\end{abstract}

Keywords: Fatigue; heat treatment; hot-work tool steel

\section{Introduction}

Machinery parts are frequently subject to periodic loads and stresses which can cause them to fail under stresses much below their critical tensile and yield stress. The phenomenon causing this failure is called fatigue. It is a crucial element confining the work life of machinery parts along with other fundamental mechanisms such as wear, tear and plastic deformation ${ }^{[1]}$.

In the context of alloyed steel and hot metal forming, the most important component of any process usually reveals to be the die, since its requirement of exceptional precision and reliability increase the cost. Dies generally experience rather high cyclic temperatures variations and mechanical loading; they work in erosive/corrosive environment ${ }^{[2,3]}$ and consequently suffer mechanical and thermal fatigue ${ }^{[4,5,6,7]}$. In an attempt to prolong their working life, improve efficiency and reduce cost of processing; they are produced of hot work steel material. [8,9].

It is commonly known that fatigue is initiated by shallow tiny cracks which form on the surface of the hot work steel under cyclic stress [10,11.12]. There is extensive research conducted on hot work steels to expectantly devise solutions to extend their work life by constraining/suspending crack propagation. They introduce evaluations of different types of steels under certain hot work conditions, the effects of different service temperatures, die geometry complexity and surface improvement tools, methods of crack (heat checking) repairs, heat treatment solutions (sequences of quenching and tempering) to enhance various properties of hot work steel such as strength, toughness, ductility, surface quality, microstructural composition and combinations thereof $[10,13,14,15,16,17]$. On the other hand, room temperature work conditions are also common for hot work steel machine parts. Therefore, in addition to high service temperature fatigue behavior investigations, fatigue under non-high temperature service conditions should also be studied and derived knowledge should be included in designing. 
The properties renowned for allowing a material to better resist to thermal fatigue are low coefficient of thermal expansion, high thermal conductivity, high hot yield strength, good tempering resistance, high creep strength, high dimensional stability, resistance to shocks, adequate ductility and toughness ${ }^{[16,18]}$. The importance of these factors depends on the particular hot work process. A study that has been carried out on a martensitic chromium hot work steel, with samples austenitized under four different temperatures and subsequently tempered, revealed that thermal fatigue crack growth is strongly influenced by the austenitizing temperature and maximum test temperature, i.e. service temperature. Furthermore, it has been concluded that thermal fatigue resistance is better with higher temper resistance on high maximum cycle temperatures and better with higher toughness and ductility in lower cycle temperatures (where service temperature does not exceed $600{ }^{\circ} \mathrm{C}[16,19,20]$. This supports the fact that each hot work process can have a different suitable material specific to its requirements. It suggests that in addition to choosing the right material for a process, choosing the right heat treatment is also critical issue. Considering the operational requirements of a process, a specifically tailored heat treatment procedure can allow enhancements on the hot work tool steel mechanical properties and microstructure to optimize its thermal fatigue resistance. There are some researches to obtain and/or predict the real behavior of steels under complex loading conditions, also [18,21]. Another work ${ }^{[22]}$ more explicitly reveals that austenitizing and tempering treatments are collectively effective on the microstructure and fracture resistances. However, while changing austenitizing temperature does not impose a significant change in fatigue resistance, elevating tempering temperature affects fracture toughness and crack propagation remarkably.

Based on these facts, this study aimed to explore fatigue behavior of the commonly-used H13 hot work tool steel at room temperature service conditions, after being exposed to various sequences of heat treatment after austenitizing.

\section{Materials and Experimental Procedure}

\subsection{Materials}

AISI H13 hot work steel grade was used for this study which has a nominal chemical composition of (weight \%) $0.47 \mathrm{C}, 0.87 \mathrm{Si}, 0.35 \mathrm{Mn}, 5.22 \mathrm{Cr}, 1.37 \mathrm{Mo}, 0.25 \mathrm{Ni}, 0.85 \mathrm{~V}, 0.01 \mathrm{~F}, 0.001 \mathrm{~S}$, $0.02 \mathrm{Al}, 0.03 \mathrm{Co}, 0.09 \mathrm{Cu} 0.005 \mathrm{Ti}$ and $0.07 \mathrm{~W}$. ASTM-E466 hour type specimens were manufactured with main diameters of $9.35 \mathrm{~mm}$ and thinnest section (breaking point) smallest diameters of $6.35 \mathrm{~mm}$ (Figure 1). AISI H13 grade steel has high toughness and it is able to keep its thermal conductivity, hardness and wear resistance in high temperatures. It has high resistance to crack start and initiation. It can be quenched to a certain extent and is usually used in light metal compression moulds and extrusion presses as die, cylinder, feeder, matrix, punch and jacket after nitration. It is also used as manufacturing material for very abrasive plastic and small forging dies. Molybdenum and chromium carbides within its composition decompose after one hour austenitization at $1010{ }^{\circ} \mathrm{C}$ whereas vanadium carbides (VC) remain undissolved. Cooling in room temperature creates a microstructure of martensite, residual austenite and a small amount of bainite. Double tempering at 550-635 ${ }^{\circ} \mathrm{C}$ can transform the residual austenite into tempered martensite. Here, the first tempering transforms the residual austenite formed by austenitizing and air cooling into martensite whereas second tempering transforms this new martensite into tempered martensite. Double tempering is essential in achieving maximum dimensional stability. H13 comprises of relatively low-alloy, ferrite dispersed alloy carbides $\left(\mathrm{Mo}_{6} \mathrm{C}, \mathrm{Cr}_{2} \mathrm{C}_{3}, \mathrm{VC}\right) 3.5 \%$ by weight ${ }^{[17,23]}$.

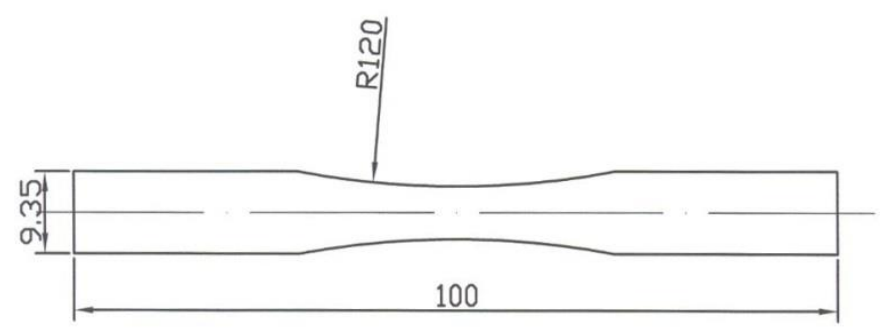


Figure 1. Specimen Dimensions

\subsection{Experimental Procedure}

\subsubsection{Heat Treatments}

250 specimens were prepared, 200 of which were divided into 4 sets and subject to four different sequences of heat treatment. All specimens were properly equipped in threes by connecting steel wires. Four sets of 50 specimens were subject to preheating, austenitizing, quenching and tempering sequences as shown in Table 1. Preheating treatments were included in order to avoid the risk of material deformation which might result from directly facing $1020{ }^{\circ} \mathrm{C}$ temperature. Quenching processes were made in GS-550 bath at $550^{\circ} \mathrm{C}$. First tempering temperature was selected to be $550^{\circ} \mathrm{C}$ since $\mathrm{H} 13$ steel reaches its maximum toughness at this temperature [6,24]. Second tempering temperature in $3^{\text {rd }}$ sequence was selected to be $610{ }^{\circ} \mathrm{C}$ since at this temperature, specimens reached the toughness values of the material which are commonly used in extrusion and injection dies in the market. Third tempering temperature in $4^{\text {th }}$ sequence, on the other hand, was selected to be $635^{\circ} \mathrm{C}$ since at this temperature, specimens reached the toughness values of the material which are commonly used in forging dies in the market. As is seen, all treatments are common treatments in the market and their effects on the thermal fatigue behavior on the H13 metal were investigated. A fifth set of non-heat treated specimens was also included.

Table 1 Heat treatment process sequence details.

\begin{tabular}{|c|c|c|c|c|}
\hline Sequence & $1^{\text {st }}$ & $2^{\text {nd }}$ & $3^{\text {rd }}$ & $4^{\text {th }}$ \\
\hline Number of specimen per sequence & \multicolumn{4}{|c|}{50} \\
\hline $1^{\text {st }}$ preheating & \multicolumn{4}{|c|}{$250-300^{\circ} \mathrm{C} / 20 \mathrm{~min}$} \\
\hline $2^{\text {nd }}$ preheating & \multicolumn{4}{|c|}{$850-860^{\circ} \mathrm{C} / 20 \mathrm{~min}$} \\
\hline Austenitizing & \multicolumn{4}{|c|}{$1020^{\circ} \mathrm{C} / 15 \mathrm{~min}$} \\
\hline Quenching GS 550 bath & \multicolumn{4}{|c|}{$1020^{\circ} \mathrm{C}-550^{\circ} \mathrm{C}$} \\
\hline $1^{\text {st }}$ tempering & - & \multicolumn{3}{|c|}{$550^{\circ} \mathrm{C} / 120 \mathrm{~min}$} \\
\hline $2^{\text {nd }}$ tempering & - & - & \multicolumn{2}{|c|}{$610^{\circ} \mathrm{C} / 120 \mathrm{~min}$} \\
\hline
\end{tabular}

\subsubsection{Fatigue Tests}

Surface treatments of sanding (by grit sizes of 200,400, 800 and 1200 in sequence) and polishing by abrasive powder $(1 \mu \mathrm{m})$ and baize were applied to specimens in order to eliminate residues such as oxide layer.

In this study, a R.R. Moore type rotating bending fatigue test machine (Figure 2) was used for tests. Required loads with respect to desired stress values were calculated using Equation 1 [25]. Fatigue tests were executed with respect to the acquired minimum/maximum loads and fatigue lives of specimens were determined accordingly. All tests were conducted on a rotation rate of $6000 \mathrm{rpm}$.

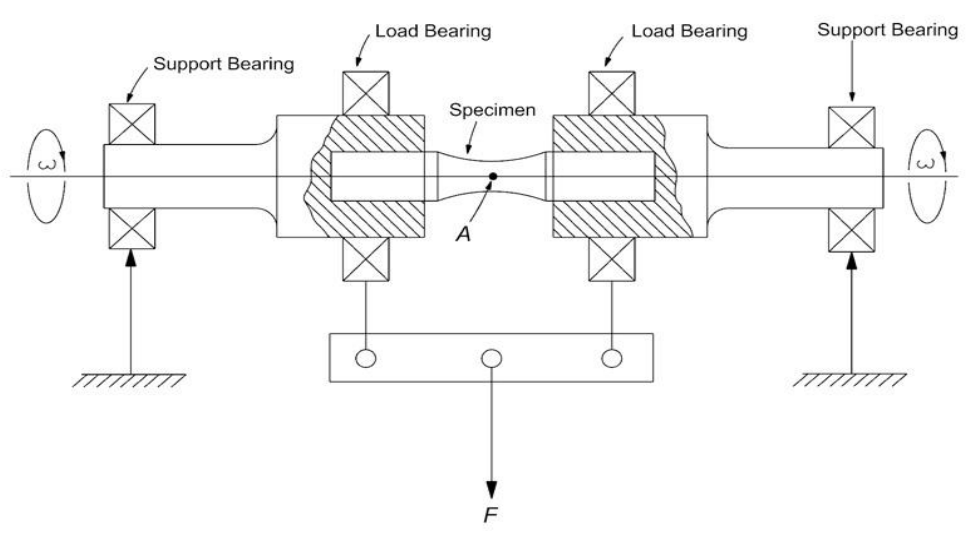

Figure 2. Schematic View of the Rotating Bending Fatigue Test Machine (12000 max. rpm). 


$$
\sigma=16 \cdot W \cdot L / n \cdot D^{3}
$$

Where $\sigma$ represents the stress value on the outermost surface of the specimen at the minimum section, $\mathrm{W}$ represents the total load applied on the specimen, $L$ represents the moment lever (distance between the point of the applying load and the bearing support) and $D$ represents the smallest diameter. Since $L$ is held constant, this equation yields only one $W$ value for a given diameter and stress requirement. It was calculated separately for each specimen since even tiny differences in diameter yielded different stress values.

\section{Results and Discussion}

\subsection{Effects of Heat Treatment Temperature on the Grain Structure and Hardness}

Vanadium, chromium and molybdenum alloys of H13 hot work tool steel are found inside the carbide structure. From the xrd analysis (Figure 3), there is also an increase in the density of the peaks of $\mathrm{CrC}$ and $\mathrm{MoC}$ after heat treatment. In the literature, it is known that the M23C6 and M7C3 are carbides made of Fe and $\mathrm{Cr}$ [22]. MC type is a carbide alloy made of $\mathrm{V}$ and Mo elements. These are mostly VC type ${ }^{[6]}$. These results are in parallel with those of XRD analysis, given in Figure 3. CrC peaks are shown in all the experiment. The presence of the alloying elements also changes the hardness. From Figure 4 it can be seen that the hardness of H13 steel is increased with quenching temperature. There are about $10 \%$ alloying elements in $\mathrm{H} 13$ steel. In the process of heating, alloying elements in the form of carbide gradually integrate into the austenitic lattice ${ }^{[28}$. As is known from the literature, the increase of the heat treatment temperature increases the integration of the alloying elements [29,30]. As seen in Figure 3 and 4, the alloying elements increased the hardness of the martensite structure. Martensitic transformation is a diffusion-free transformation. Thus, during martensitic transformation, carbon and alloy elements remain in the martensite cage. This. situation increases the hardness. As shown in Figure 4, the presence of $\mathrm{CrC}$ and $\mathrm{MoC}$ in the structure, in particular 1 and 2, increases the hardness. In order to see the effects of heat treatments on the structures of the specimens, one specimen of each set was examined by scanned electron microscopy (SEM). Figure 5 shows the original microstructure of $\mathrm{H} 13$ hot worked tool steel. The original structure shows carbide grains in ferrite with a grain size of $8-10 \mu \mathrm{m}$, and the perlite grains are also observed.

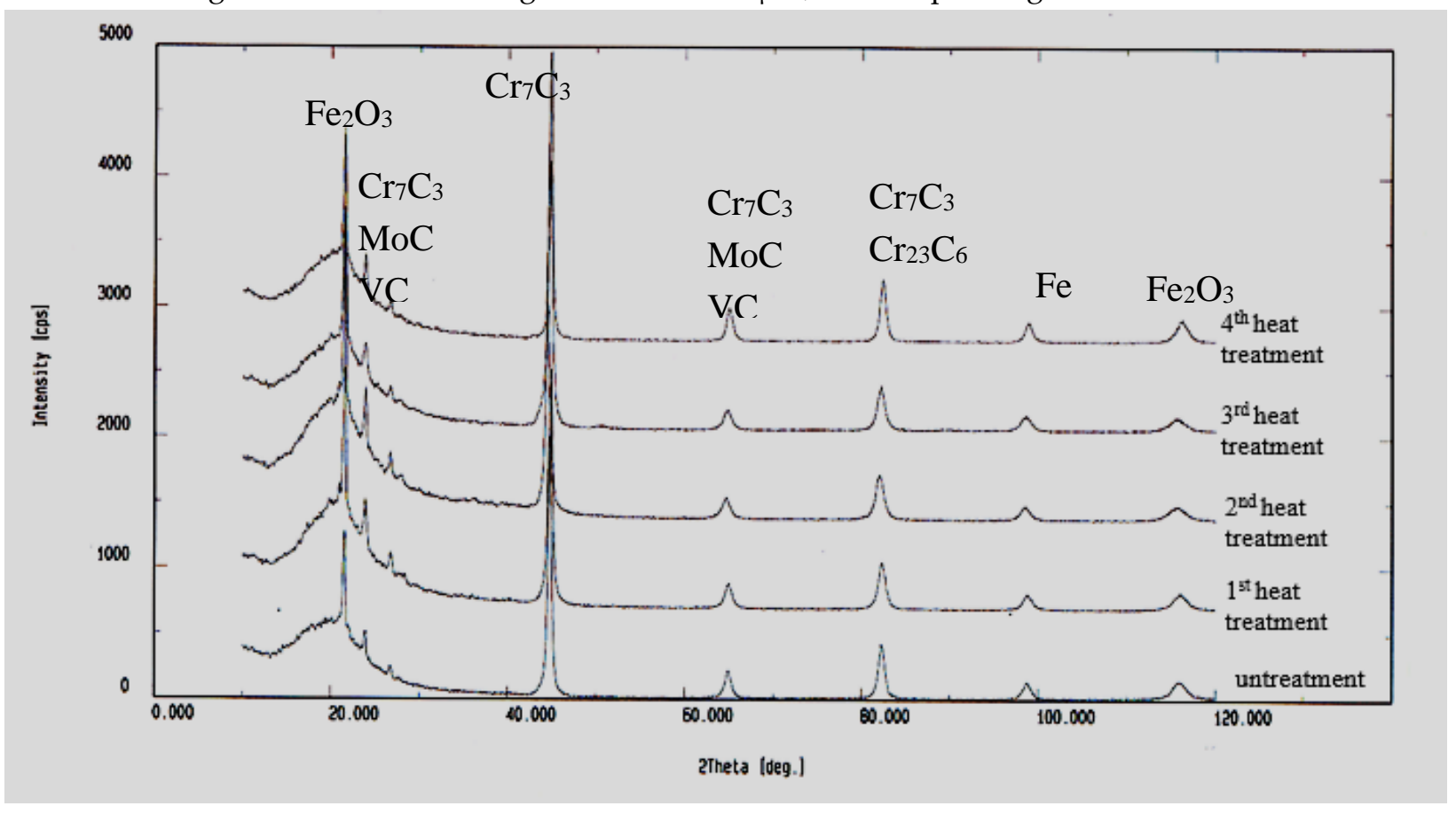

Figure 3. XRD analysis. 


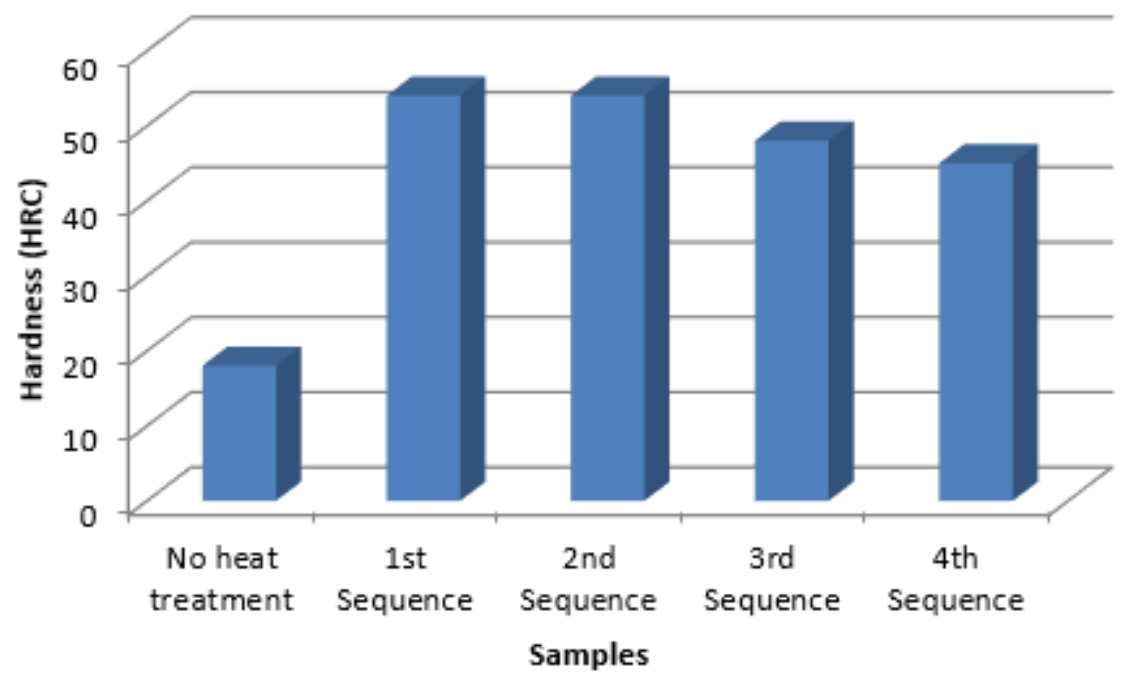

Figure 4. The hardness of the materials.
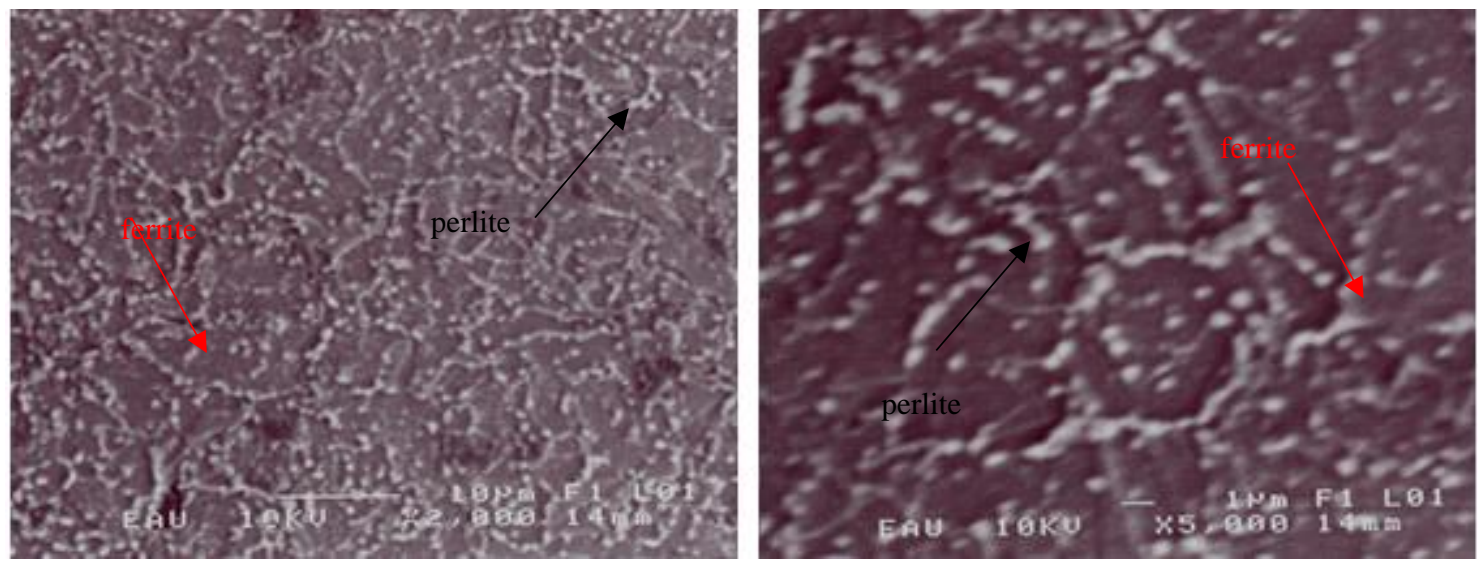

Figure 5 Microstructure of specimen set with no heat treatment.

Figure 6 shows that quenching, $1^{\text {st }}$ heat treatment sequence, causes the grain boundaries to disappear and their size to decrease by \%50. Martensite structure, obtained by quenching, is also visible. Also Figure 6 shows that Austenite grains are tiny and uniform in Figure 6. It is known from the literature that after curing, the double tempering of $\mathrm{H} 13$ steel increases the fatigue strength to 720 $\mathrm{MPa}$. This value is the highest in the study. As it is known, the residual austenite is turned into tempered martensite by double tempering at the appropriate temperature [23]. This helps to explain the maximum fatigue strength at double tempering. Moreover, the formation of more stable carbide by double tempering can explain the mechanical properties of the material and thus the fatigue strength ${ }^{[3,5]}$. The carbides herein are found to be $\mathrm{Mo}_{6} \mathrm{C}, \mathrm{Cr}_{2} \mathrm{C}_{3}, \mathrm{VC}$ and this is in accordance with the literature $[6,7,17,23]$.

Comparing 2nd sequence specimens with 1st sequence specimens (Figure 7), it can be found that grain sizes are more visible and grains are more apparent in the former. Martensitic structure characteristics are also more obvious. It appears to be evident that the formation of a network in the thickened grain boundaries occurs Figure 7. Figure 7 shows the ferrite type M6C, M23C6, M7C3 and MC type of carbides. M6C types are mainly carbides of Fe, $\mathrm{Cr}$ and Mo alloys. M23C6 and M7C3 types are the carbides made by Fe and $\mathrm{Cr}$ elements [15]. MC types are carbides made of $\mathrm{V}$ and Mo alloying elements. The VC type is predominant ${ }^{[16]}$. The results of XRD analysis of the steel are parallel to this information ${ }^{[27]}$. 

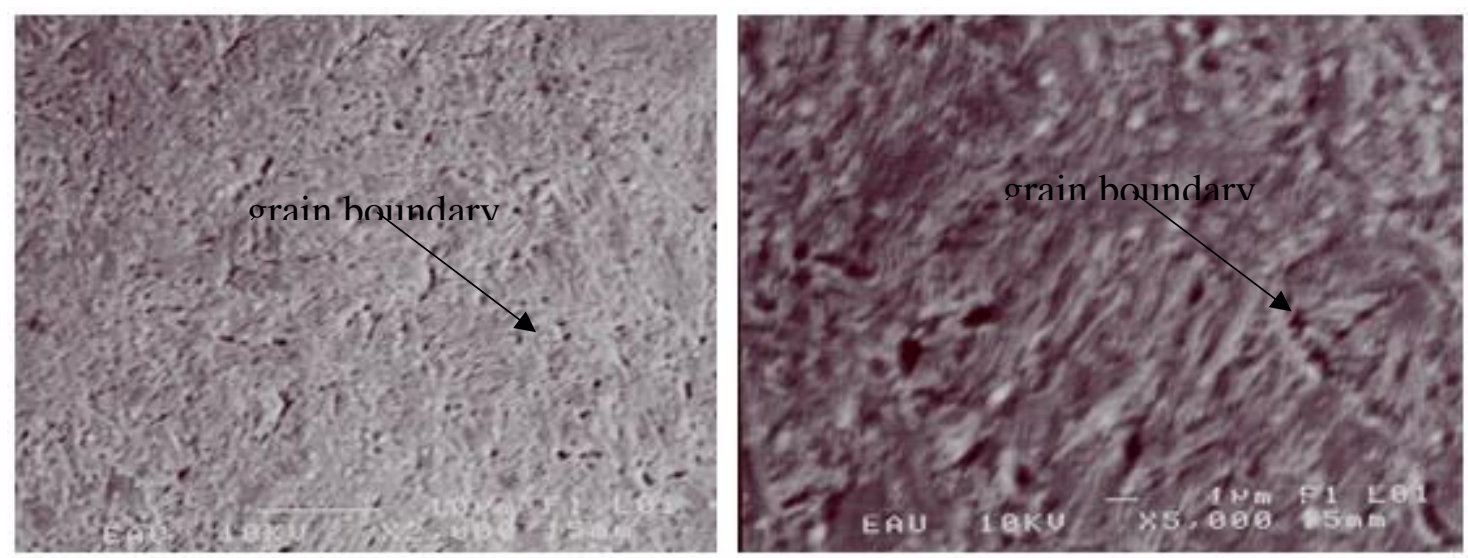

Figure 6 Microstructure of specimens of $1^{\text {st }}$ heat treatment sequence.
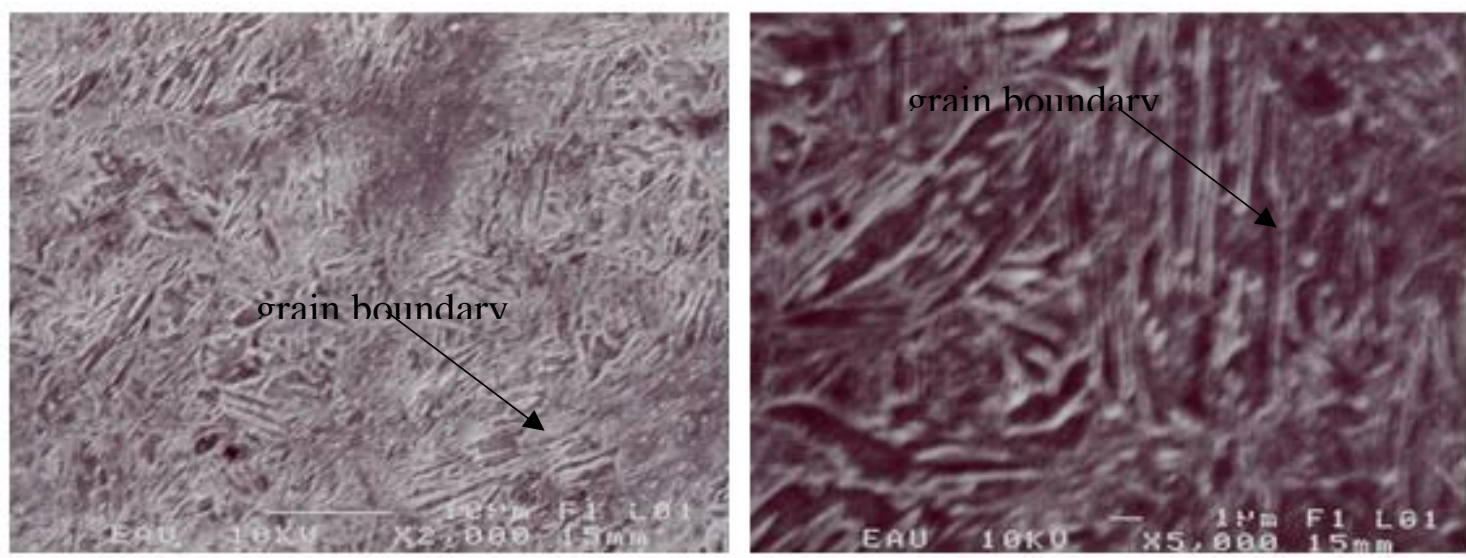

Figure 7 Microstructure images of $2^{\text {nd }}$ heat treatment sequence specimens.

Figure 8 shows further disappearance of grain boundaries compared to that of $2^{\text {nd }}$ sequence specimens. Most of the carbides are dissolved in solid solution during austenitization (Figure 8). The microstructure reveals the tempered martensite in the dispersion of the dense carbides (insoluble carbides during the austenization) combined with the dispersion of the fine carbides (carbides which prevent dissolution during tempering). Coarse carbide particles are expected to be $\mathrm{M}_{7} \mathrm{C}_{3}(\mathrm{eg} \mathrm{CrC})$. It is clearly seen from Figure 4 that coarse carbides remain as an impediment to austenite grain growth. This causes high wear resistance. Furthermore, the shape and distribution of these carbide particles also cause anisotropic mechanical properties [30]. Coarse carbide particles are M6C, M23C6, M7C3 type carbides. MC type carbides (VC) are insoluble because they are more resistant carbides. Internal structure after hardening; The residue consists of austenite, martensite and alloy carbide ${ }^{[27]}$.
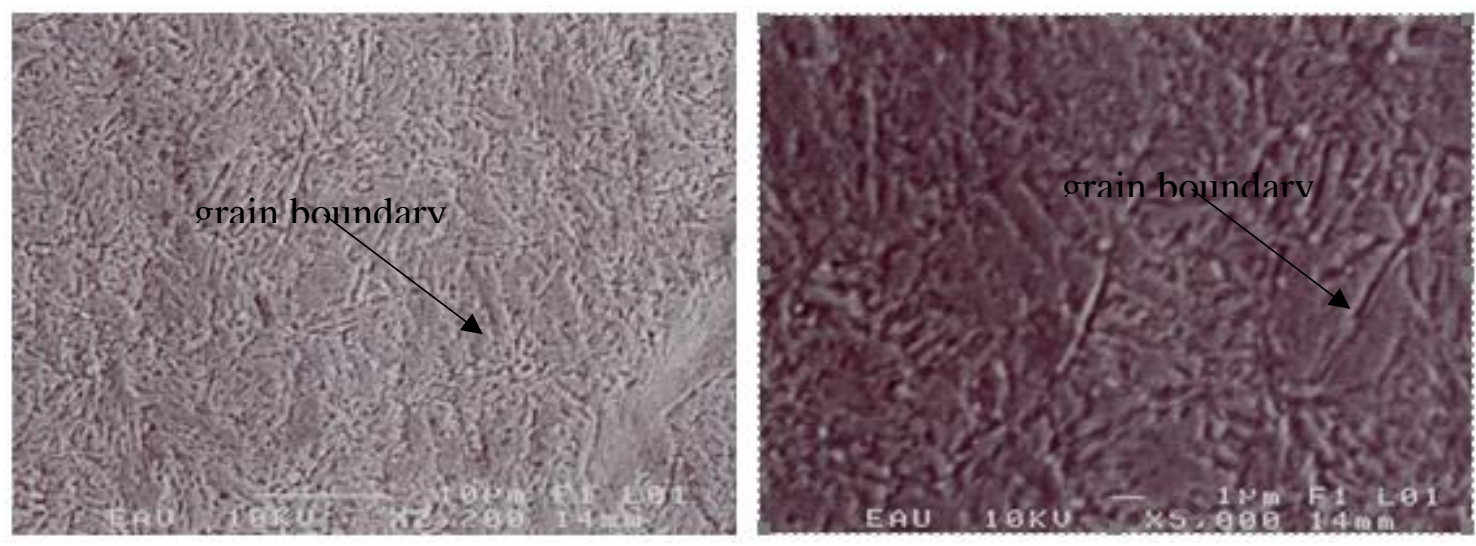

Figure 8 Microstructure images of $3^{\text {rd }}$ heat treatment sequence specimens. 
It is apparent, Figure 9, that specimens of 3rd and 4th sequences have similar microstructures. Compared to 2 nd sequence specimens, however, grain boundaries are less apparent. Figure 9 shows that smaller grains formed and their growth were reduced at the grain boundary to allow for the formation of a fine-grained structure. After curing, $\mathrm{M}_{7} \mathrm{C}_{3}\left(\mathrm{Cr}_{7} \mathrm{C}_{3}\right)$ type carbides dissolve by tempering at $550^{\circ} \mathrm{C}$. M7C 3 type carbides show a secondary hardening effect. Therefore, despite the decrease in carbon ratio, hardness does not decrease. The residue turns into austenite martenzite. As shown in Figure 9, martensite is not planar but linear. Line type martensite forms due to the reduced carbon content, caused by the decomposition of the carbides ${ }^{[27]}$.
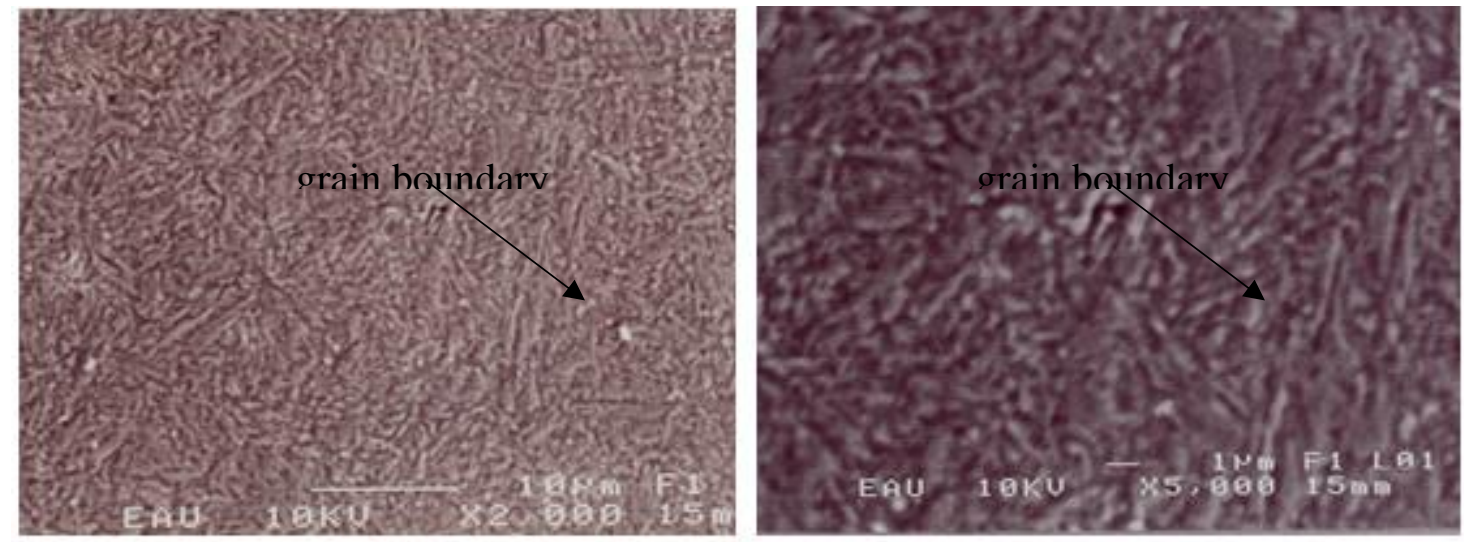

Figure 9 Microstructure images of $4^{\text {th }}$ heat treatment sequence specimens.

\subsection{Fatigue Test Results}

Maximum stress values to be applied were determined to be $70 \%$ of the tensile stress of the bare material, in accordance with literature. Woehler curves were generated accordingly. Infinite life values were determined by increasing applied stresses by smal increments from the point where curve slopes started to decrease until $10^{6}$ cycles were reached. Woehler curves show that applied heat treatments had positive effects on the fatigue strength of $\mathrm{H} 13$ hot work tool steel.

In order to be able to understand the effects of heat treatments on the fatigue strength of the material and to make comparisons, non-heat treated $\mathrm{H} 13$ specimens were tested first. Woehler curves are shown in Figure 10. Testing 50 specimens of non-heat treated yielded the fatigue strength value of $470 \mathrm{MPa}$. The fatigue strength of heat-treated of specimens by $2^{\text {nd }}, 3^{\text {rd }}, 4^{\text {th }}$ sequences are respectively 630, 720, $710 \mathrm{MPa}$. A comparison of Woehler curves of all specimens tested revealed that fatigue strength of $\mathrm{H} 13$ hot work tool steel was overall positively affected by applied heat treatments. There is not a notable strength difference between specimen sets of sequence 1 and 2, in the same way, no notable difference between sets of sequence 3 and 4 .

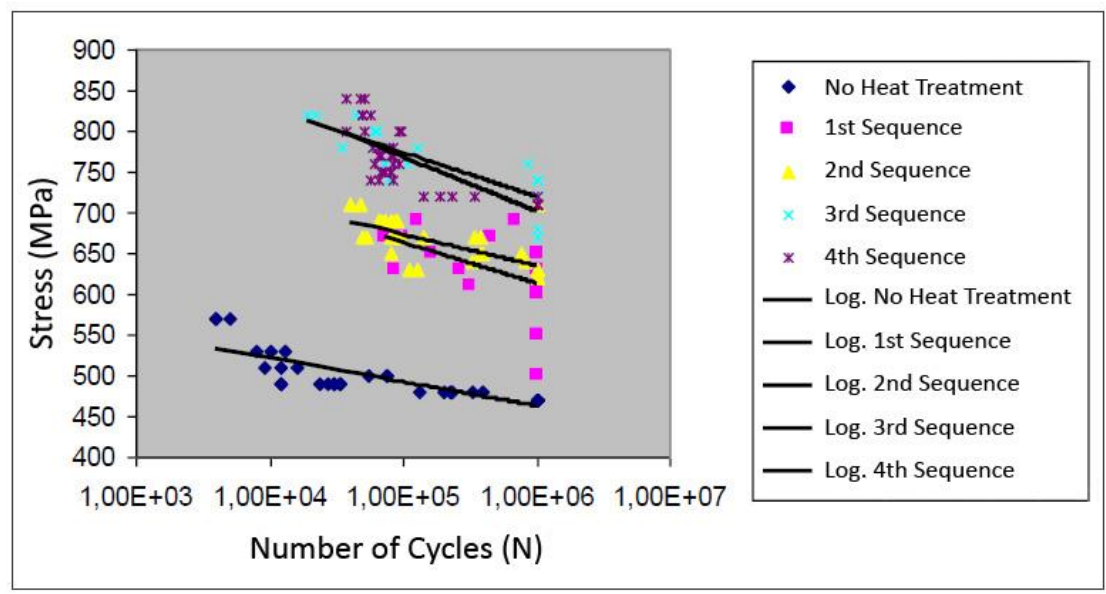

Figure 10 Woehler curves of all specimen sets. 
Table 2 shows the significant (approx. 45\%) fatigue strength increase due to heat treatment on specimens. This result is parallel to the fact that mechanical properties of steel such as tensile strength are improved by heat treatment. Alloy carbide elements $\mathrm{Cr}$, Mo and V are better diffused in the microstructure consequently resulting in increased fatigue strength. Hardness values also show a significant increase after quenching, which can be explained as a result of the dissolution of the most carbides and their being in solid solution form in the martensitic structure (Figure 3 and Figure 4). Tempering, however, causes slight softening of the material, due to the density reduction of microstructural defects such as dislocations $[4,24,26]$.

Table 2 Fatigue strength and hardness values of all specimen sets.

\begin{tabular}{|c|c|c|c|c|c|}
\hline & No heat treatment & $1^{\text {st }}$ Sequence & $2^{\text {nd }}$ Sequence & $3^{\text {rd }}$ Sequence & $4^{\text {th }}$ Sequence \\
\hline Stress (MPa) & 470 & 610 & 630 & 720 & 710 \\
\hline Hardness (HRC) & 18 & \multicolumn{2}{|c|}{$53-54$} & $47-48$ & $44-45$ \\
\hline
\end{tabular}

Specimens which were tempered at $550{ }^{\circ} \mathrm{C}$ for two hours ( $2^{\text {nd }}$ Sequence) had a fatigue strength of $630 \mathrm{MPa}$ which was close to that of specimens which were solely subject to quenching ( $1^{\text {st }}$ Sequence). Contribution of tempering in fatigue strength improvement was rather small (approx. 20 $\mathrm{MPa}$ ) which concluded that a single tempering process following quenching did not have any significant effect on fatigue strength.

A second tempering process of two hours at $610^{\circ} \mathrm{C}$ following the first tempering of two hours at $550{ }^{\circ} \mathrm{C}$, however, resulted in the maximum fatigue strength value of all the specimen sets by 720 MPa. This supports the before discussed fact that, double tempering of this steel at suitable temperatures provides residual austenite to transform into martensite ${ }^{[23]}$. It further proves that, by the second tempering, newly formed carbides become more stable and material obtains better mechanical properties, hence better fatigue strength ${ }^{[24]}$. As seen Figure 3, carbides in this situation were determined to be $\mathrm{Mo}_{6} \mathrm{C}, \mathrm{Cr}_{2} \mathrm{C}_{3}$ and $\mathrm{VC}$, which conforms with literature [23].

Raising the second tempering temperature to $635^{\circ} \mathrm{C}$ in $4^{\text {th }}$ sequence specimens yielded a fatigue strength of $710 \mathrm{MPa}$, which is close to that of $3^{\text {rd }}$ sequence specimens. This shows that this tempering temperature does not provide a significant contribution in fatigue strength. It might also suggest that $635^{\circ} \mathrm{C}$ represents the temperature above the optimum temperature, where fatigue strength actually begins to drop.

\subsubsection{Fracture surfaces}

Fifty samples of each group have been used for the fatique experiments. The avareges value of selected samples are given in the Figure 11-15 for the each group. A comparison within a range where non-heat treated specimens represent the lowest limit and double tempered specimens represent the highest limit shows that each heat treatment sequence provided a certain fatigue strength improvement (Figure 10). However, According to the Figure 11, Figure 12, Figure 13, Figure 14 and Figure 15; this improvement was not significant between specimens of $1^{\text {st }}$ through $2^{\text {nd }}$ sequences; and also $3^{\text {rd }}$ through $4^{\text {th }}$ sequences. In other words, solely quenching creates nearly the same effect with tempering at $550^{\circ} \mathrm{C}$ for two hours after quenching; which is also true for tempering at $610^{\circ} \mathrm{C}$ for two hours and tempering at $635^{\circ} \mathrm{C}$ for two hours after quenching followed by tempering at $550^{\circ} \mathrm{C}$ for two hours. However, it was clearly shown that double tempering provided the maximum fatigue strength. The fact that the residual austenite, which was formed by the first tempering, transformed into martensite by the second tempering played a critical role in this. It further supported that a more homogenized microstructure and smaller grain sizes delivered by heat treatments are effective factors in terms of fatigue strength improvement.

A more stable microstructure is to primarily affect the strength and micro scale properties of the material. A more homogeneous distribution of the carbides and decreased grain size are to enable the yield strength to improve. Plastic deformation is caused by shear movements and an increasing number of plastic deformations means an increase in the density of dislocations and their interactions 
with point defects and secondary phases. Smaller grain size therefore makes dislocations more difficult to happen since they then require interacting with larger amount of grain boundaries.

Crack propagation direction in microscopic level is to depend on microstructural properties, as is the very initiation of cracks itself. This dependence in microstructure plays a determinant role also in the macrostructural condition, which explains the influence of heat treatment on the microstructure consequently resulting in improved fatigue resistance.

As seen in Figure 11, fatigue cracking has started in many places on the surface at different circumferential planes and progressed in different amounts and planes. Cracks (tooth marks) are seen in the form of cracks. Fractures, as seen in Figure 11b and c, were formed by the cracking of the grain boundaries of the carbides located at the grain boundaries, causing cracks in the intergranular fracture type. The samples are broken at $470 \mathrm{MPa}$ fatigue resistance and $34000 \mathrm{rpm}$ cycle value.
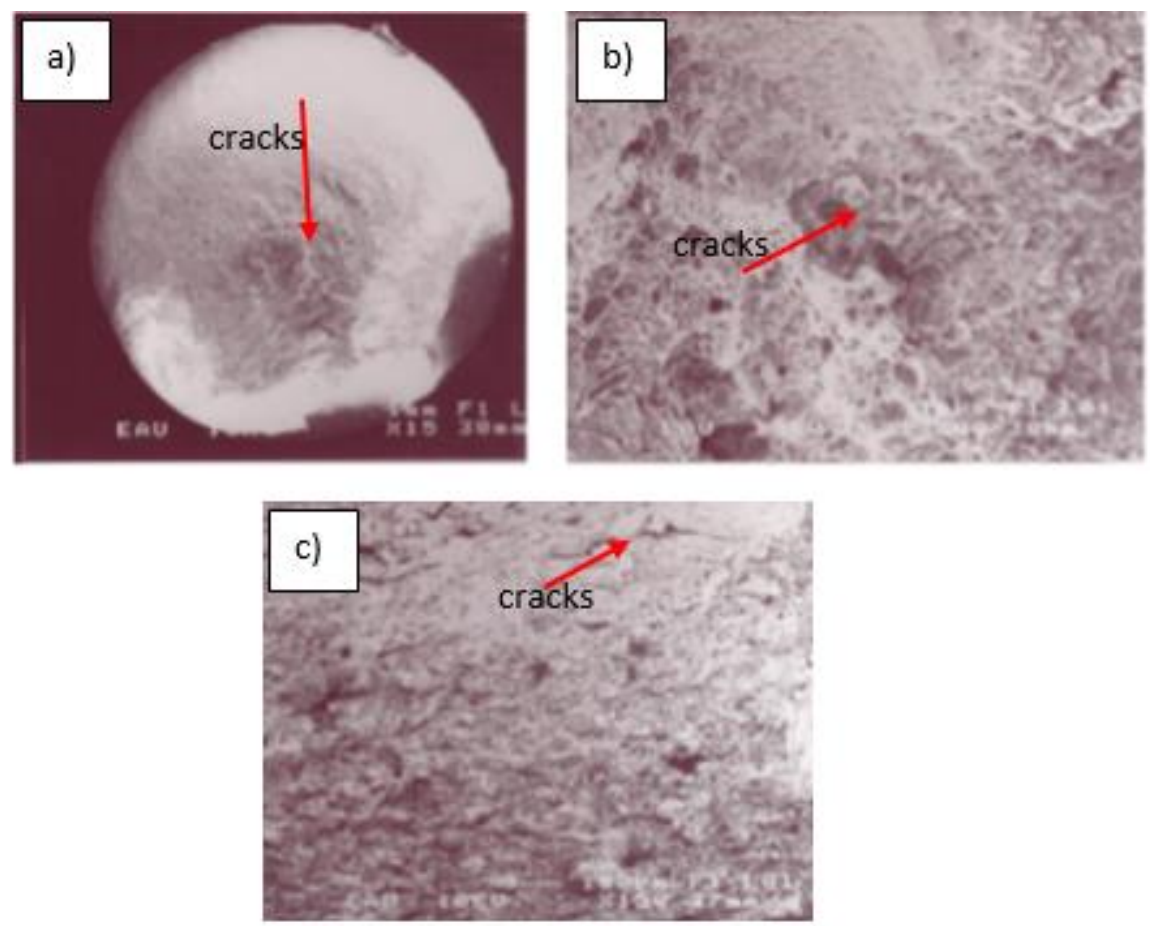

Figure 11. Breaking point surface images of specimens with no heat treatment a) Macro image of breaking point surface, b) Fatigue area, c) Breaking point area

Figure 12 shows a circular arc indicating the transition from the fatigue zone to the fracture site. The fatigue zone is brighter than the fracture zone due to friction of the surfaces as the crack progresses. As seen in Figure $12 \mathrm{~b}$ and c, it progressed along fractured grain boundaries and caused intergranular fracture. The carbide particles in the grain boundaries weakened the grain boundaries. The macro region of the fracture surface shows the slip region; the width of the region is small as seen. The low width of the slip zone means that the ductility of the material decreases. Samples belonging to this group had only hardening process. A rapid crack advance is observed in the slip area. The glide zone has a relatively smooth appearance. At the point the fracture begins, the shear zone is absent. The shear zone forms on places where the crack progressing within the section reaches the surface. The samples are broken at $690 \mathrm{MPa}$ fatigue resistance and $318000 \mathrm{rpm}$ cycle value.

Figure 13 shows the circular arc separating the fatigue zone from the fracture site. The area of refraction is more matte. Plastic deformation during breakage causes matte appearance. As seen in Figures $13 \mathrm{~b}$ and $\mathrm{c}$, the carbide particles are located at the grain boundaries causing intergranular breakage. It advances following the weakest planes in the cracked material. Carbide particles in the grain boundaries have reduced grain boundaries. The samples are broken at $670 \mathrm{MPa}$ fatigue resistance and $340000 \mathrm{rpm}$ cycle value. 

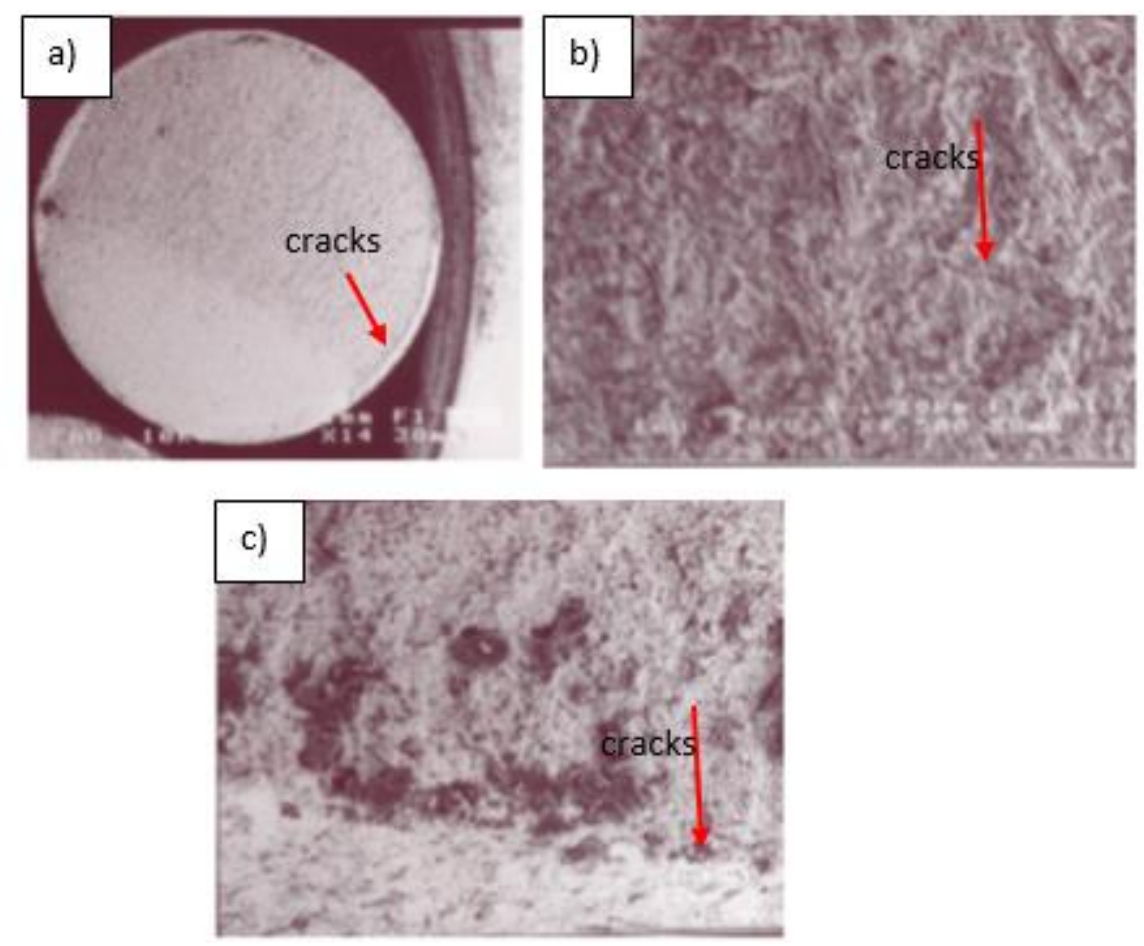

Figure 12. Breaking point surface images of $1^{\text {st }}$ heat treatment sequence specimens a) Macro image of breaking point surface, b) Fatigue area, c) Breaking point area.
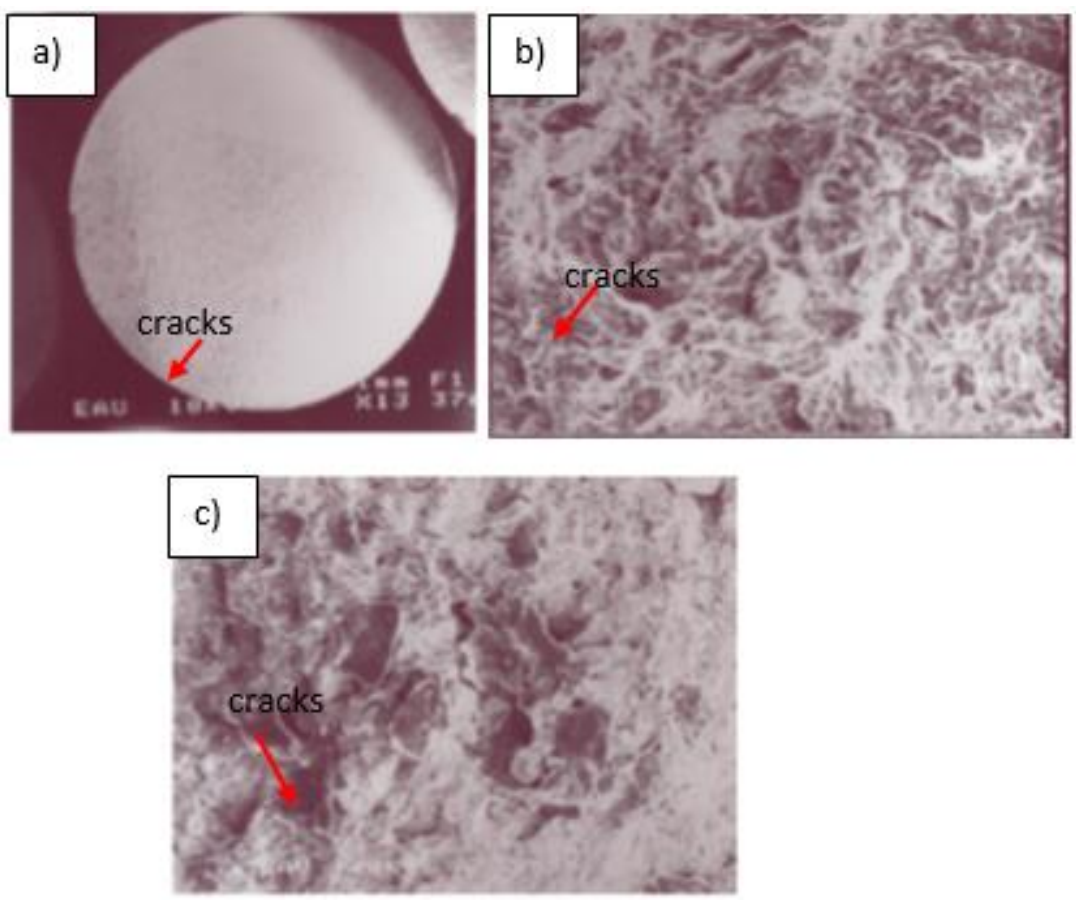

Figure 13 Breaking point surface images of $2^{\text {nd }}$ heat treatment sequence specimens a) Macro image of breaking point surface, b) Fatigue area, c) Breaking point area. 

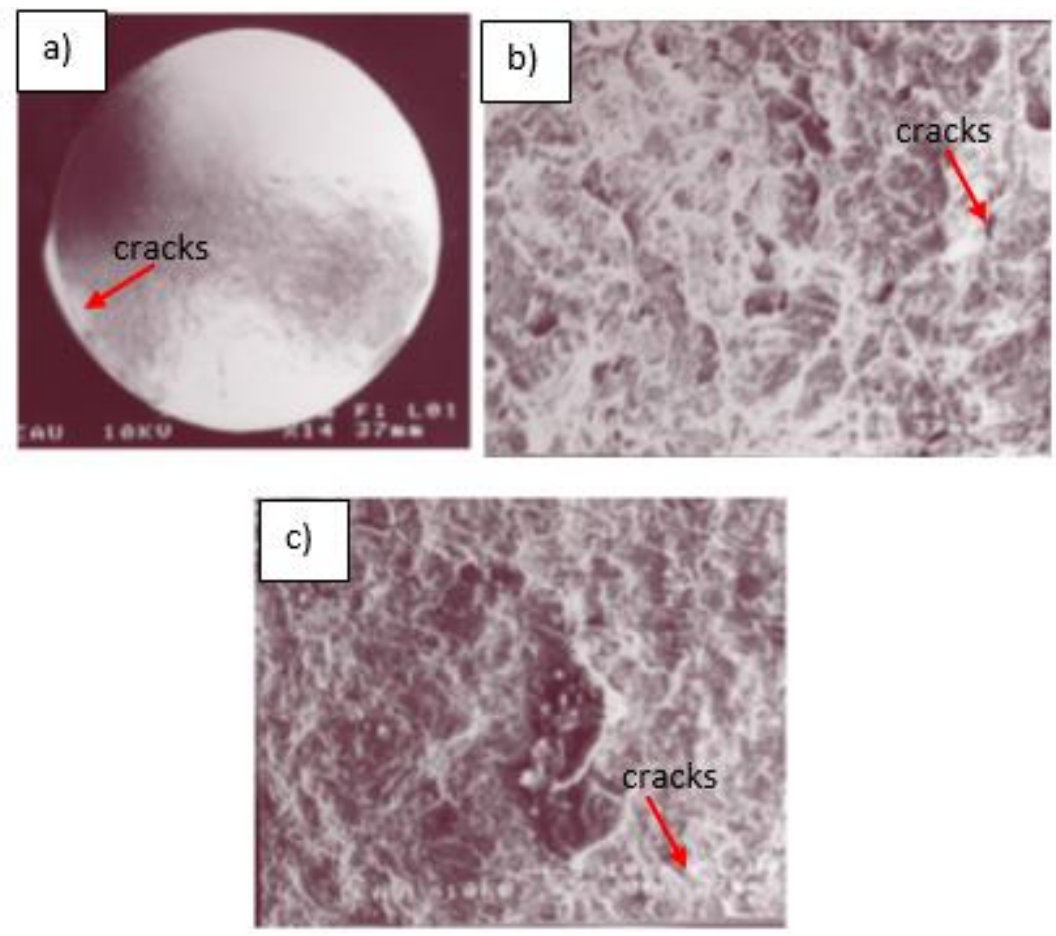

Figure 14 Breaking point surface images of $3^{\text {rd }}$ heat treatment sequence specimens a) Macro image of breaking point surface, b).Fatigue area, c) Breaking point area
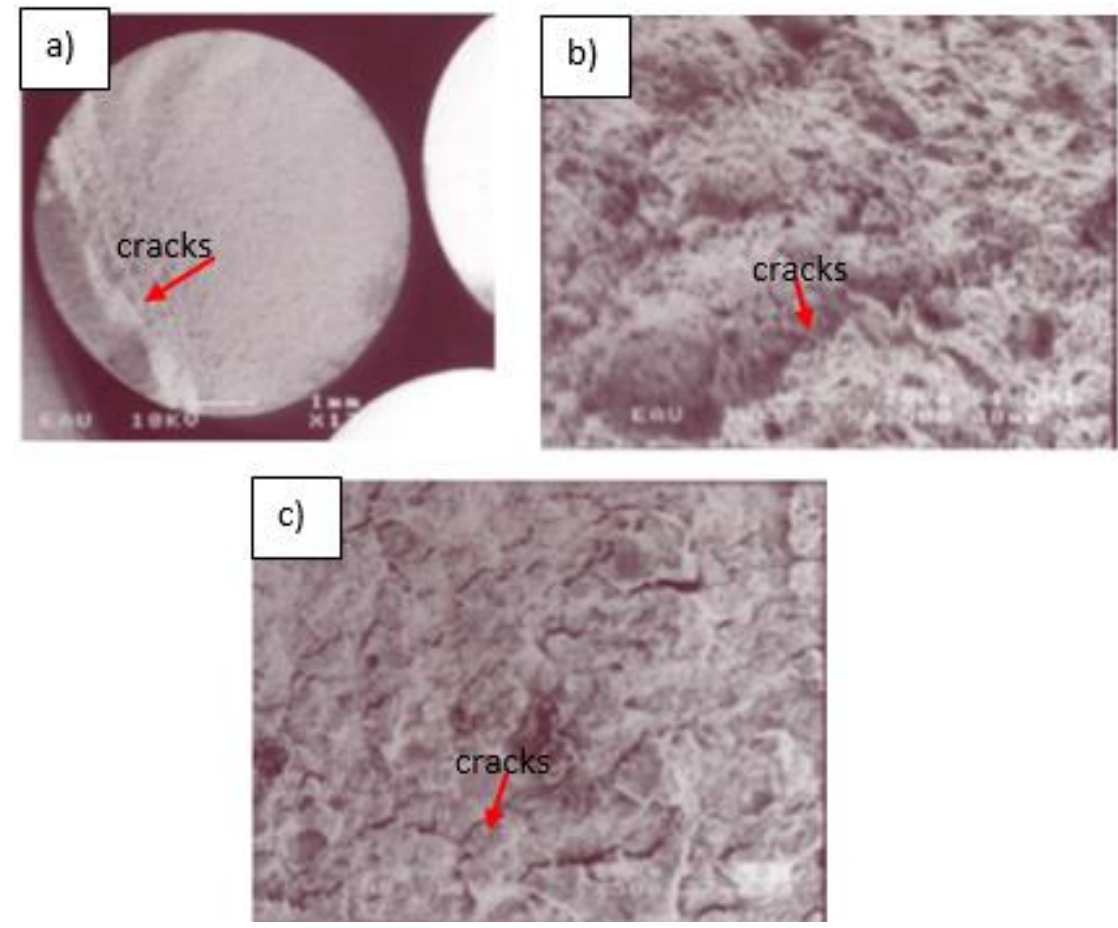

Figure 15 Breaking point surface images of $4^{\text {th }}$ heat treatment sequence specimens a) Macro image of breaking point surface, b). Fatigue area, c) Breaking point area

As seen in Figure 14, the shear zone was formed on the fracture surface. Shear zone means plastic deformation when damage occurs. It progressed between the cracked grains and caused intergranular fractures due to the carbides in the grain boundary. However, the slip region is wider than the I group ( $1^{\text {st }}$ heat treatment sequence specimens) indicating that ductility is increased. The samples are broken at $760 \mathrm{MPa}$ fatigue resistance and $130000 \mathrm{rpm}$ cycle value. 
Figure 15 shows that the samples have been damaged by intergranular fracture type. The fracture zone is clearly distinguished from the fatigue zone as seen in Fig. 15b and c. The samples are broken at $740 \mathrm{MPa}$ fatigue resistance and 180000rpm cycle value.

The fracture surfaces of all groups have common features. Fracture type and fracture spread pattern are intergranular in all groups. As the loading history of the part did not change, the loading frequency did not change and the phases were not subjected to load repetition. Consequently, fatigue lines were not seen on the fracture surfaces. On the fracture surface of the $O$ group (non heat treatment), step lines formed due to the fact that a large number of cracks merge together to form a single cracked front. The area resulting from the progression of the fatigue crack is macroscopically flat and brighter.

\section{Conclusion}

(1) The presence of the alloying elements also changes the hardness.

(2) The hardness of $\mathrm{H} 13$ steel is increased with quenching temperature.

(3) All applied heat treatments resulted in a certain improvement in the fatigue strength of the material.

(4) Only one tempering at $550{ }^{\circ} \mathrm{C}$ for two hours after quenching does not provide any significant improvement in fatigue strength over solely quenching.

(5) Increasing the second tempering temperature from $610{ }^{\circ} \mathrm{C}$ to $635^{\circ} \mathrm{C}$ did not have a particular impact on fatigue strength.

(6) Maximum fatigue strength of $\mathrm{H} 13$ was obtained by applying a double tempering heat treatment (first tempering at $550{ }^{\circ} \mathrm{C}$ for two hours and second tempering at $610{ }^{\circ} \mathrm{C}$ for two hours) after initial preheating and quenching.

(7) Fracture type and fracture spread pattern are intergranular in all groups.

(8) As the loading history of the part did not change, the loading frequency did not change and the phases were not subjected to load repetition. Consequently, fatigue lines were not seen on the fracture surfaces. On the fracture surface of the O group (non heat treatment), step lines formed due to the fact that a large number of cracks merge together to form a single cracked front. The area resulting from the progression of the fatigue crack is macroscopically flat and brighter.

\section{References}

1. BARRAU O, BOHER C, GRAS R, et al. Analysis of the friction and wear behaviour of hot work tool steel for forging. Wear, 2003, 255, 1444-1454.

2. WILZER, J, KUPFERLE, J, WEBER, et al. Influence of Alloying Elements, Heat Treatment, and Temperature on the Thermal Conductivity of Heat Treatable Steels, Steel Research International, 2015, 86, 1234-1241

3. SALEM M, ROUX S LE, DOUR G, et al, Effect of aluminizing and oxidation on the thermal fatigue damage of hot work tool steels for high pressure die casting applications, International Journal of Fatigue, 2018, 119, 126-138.

4. YEH, SH, CHIU, LH, LIN, SC, et al, AISI H13 Hot-Work Steel with Hard Chromium Plating Thermal Fatigue Behavior Evaluation, Materials Engineering and Technology, 2014, 849, 8-+

5. PUŠB G, ŽUŽEK V, LESKOVŠEK M, et al, Heat Treatment Optimization and Properties Correlation for H11-Type Hot-Work Tool Steel, Metallurgical and Materials Transactions A, 2018, 49, 455-462

6. SABINE L R, FARID M, GILLES D, et al, Role of heat-flux density and mechanical loading on the microscopic heat-checking of high temperature tool steels under thermal fatigue experiments. International Journal of Fatigue, 2013, 51, 15-25,

7. SABINE L R, FARHAD R A, Topological and metric properties of microscopic crack patterns: application to thermal fatigue of high temperature tool steels, Journal of Physics D: Applied Physics, 2013, 46, 29, 295301.

8. PERSSON A, HOGMARK A, BERGSTRÖM S J, 2004. Simulation and evaluation of thermal fatigue cracking of hot work tool steels. International Journal of Fatigue, 2004, 26, 1095-1107.

9. SHEIKH A K, ARIF A F M, QAMAR S Z, A probabilistic study of failures of solid and hollow dies in hot aluminum extrusion. Journal of Material Processing Technology, 2004 155-156, 1740-1748. 
10. YAHONG S, SATOSHI H, MASATO Y, et al, Fatigue behavior and fractography of laser-processed hot work tool steel. Vacuum, 2004 73, 655-660.

11. ZHANG, LL, LEI, LP, ZENG, P, Investigation of the Influence of Deep Rolling on the Thermal Fatigue Cracking for AISI H13 Steel, Frontiers of Mechanical Engineering and Materials Engineering II, PTS 1 and 2, 2014, 457-458, 127-130.

12. ZAHRADNIK, R, RAUDENSKY, M, Improvement of Work Roll Service Life By Microstructure Simulation, 23 ${ }^{\text {rd }}$ International Conference on Metallurgy and Materials, 2014, 297-302.

13. AKATA E, ALTINBALIK M T, ÇAN Y, Three point application in single tooth bending fatigue test for evaluation of gear blank manufacturing methods. International Journal of Fatigue, 2004, 26, 785-789.

14. DOBRZANSKI L A, MAZURKIEWICZ J, HAJDUCZEK E, et al 2001. Comparison of the thermal fatigue resistance and structure of the 47CrMoWVTiCeZr16-26-8 hot work tool steel with X40CrMoV5-1 type one. Journal of Material Processing Technology, 2001, 113, 527-538.

15. ELLIZZARI M, MOLINARI A, STRAFFELINI G, Thermal fatigue resistance of plasma duplex-treated tool steel. Surface and Coating Technology, 2001, 142-144, 1109-1115.

16. SJÖSTRÖM J, BERGSTRÖM J, Thermal fatigue testing of chromium martensitic hot-work tool steel after different austenitizing treatments. Journal of Material Processing Technology, 2004, 153-154, 1089-1096.

17. YEŞILDAL R, ŞEN S, KAYMAZ İ, Fatigue behaviour of X40CrMoV 51 at high temperature. Journal of Materials Engineering and Performance, ASM International, 2003, 12(2), 215-219.

18. FARES M L, ATHMANI M, KHELFAOUI Y, et al, An Investigation Into The Effects of Conventional Heat Treatments on Mechanical Characteristics of New Hot Working Tool Steel. Material Science Engineering, 2012, 28, 012-042.

19. HAWRYLUK, M, DOLNY, A, MROZINSKI, S, et al, Preliminary Low Cycle Studies of 1.2344 Hot Work Tool Steel Used For Forging Tools, 26th İnternational Conference on Metallurgy and Materials, 2017, 2145 2151

20. MENG, C, ZHOU, H, ZHOU, Y, et al, ]Influence of different temperatures on the thermal fatigue behavior and thermal stability of hot-work tool steel processed by a biomimetic couple laser technique, Optics and Laser Technology, 2014, 57, 57-65

21. VELAY V. BERNHART G, PENAZZI L, Cyclic behavior modeling of a tempered martensitic hot work tool steel. International Journal of Plasticity, 2006, 22, 459-496.

22. SOUKI I, DELAGNES D, LOURS P, 2011. Influence of heat treatment on the fracture toughness and crack propagation in 5\% Cr martensitic steel. Procedia Engineering, 2011, 10, 631 - 637.

23. SMITH W, Structure and Properties of Engineering Alloys, second ed., McGraw-Hill, New York, 1993.

24. LIN M, ZHAO X, HAN L, et al, Microstructural Evolution and Carbide Precipitation in a Heat-Treated H13 Hot Work Mold Steel. Metallography, Microstructure and Analysis, 2016.

25. BANNANTINE J, COMER J, HANDROCK J. Fundamentals of Metal Fatigue Analysis. Prentice Hall, New Jersey, 1990.

26. QI-C, JIANG X, MIN Z.F, et al, The Relationship Between Oxidation and Thermal Fatigue of Martensitic Hot-Work Die Steels, Acta Metallurgica Sinica (English Letters), 2018, 1.31, 692-698.

27. YJ SHI Y J, XA WU X A, JW LI J W, et al, Tempering stability of Fe-Cr-Mo-W-V hot forging die steels, International Journal of Minerals Metallurgy and Materials, 2017, 24, 1145-1157

28. GUANGHUA Y, XINMIN Y H, YANQING W, et al, Effects of Heat Treatment on Mechanical Properties of H13 Steel, Metal Science and Heat Treatment, 2010, 52, 7-8,

29. ZU-GENG J, ZAI-ZHI C, MI-NEN R, et al, Die Steel Metallurgy Industry Press 1988, 296

30. GEORGE K, Steels: Heat treatment and prosessing principles". Published by ASM International, Materials Park, OHIO 44073 